\title{
PEMANFAATAN EKOSISTEM MANGROVE BERBASIS SUSTAINABLE DEVELOPMENT GOALS (SDGS) DI DESA SANJAI KABUPATEN SINJAI
}

\author{
${ }^{1}$ Rahmat Januar Noor, ${ }^{2}$ Muhammad Imran Lapong dan ${ }^{3}$ Arnold Kabangnga \\ ${ }_{2}^{1}$ ITBM Balik Diwa Makassar, rahmat_jn@stitek-balikdiwa.ac.id \\ ${ }_{3}^{2}$ ITBM Balik Diwa Makassar, imranl@stitek-balikdiwa.ac.id \\ ${ }^{3}$ ITBM Balik Diwa Makassar, arnold@stitek-balikdiwa.ac.id
}

\author{
Article history \\ Received: 01 September 2021 \\ Revised: 03 Oktober 2021 \\ Accepted: 04 Oktober 2021

\section{Corresponding} \\ Author: \\ Rahmat Januar Noor \\ ITBM Balik Diwa Makassar, \\ Indonesia \\ Email: rahmat_jn@stitek- \\ balikdiwa.ac.id
}

\begin{abstract}
Abstrak
Keberadaan ekosistem pesisir, seperti mangrove, apabila dikelola dengan baik maka dapat memberi manfaat bagi masyarakat utamanya masyarakat sekitar. Namun tidak adanya edukasi terkait pemanfaatan ekosistem mangrove sehingga terkadang masyarakat tidak terlalu peduli dan cenderung melakukan aktivitas ekstraktif yang dapat merusak fungsi ekosistem mangrove. Desa Sanjai merupakan salah satu desa yang terletak di pesisir Kabupaten Sinjai dan memiliki ekosistem mangrove yang selama ini tidak dikelola dengan baik. Berdasarkan permasalahan tersebut maka program pengabdian ini bertujuan untuk meningkatkan pengetahuan dan keterampilan masyarakat terkait pemanfaatan ekosistem mangrove melalui konsep yang terintegrasi dengan prinsip Sustainable Development Goals yang merupakan program nasional. Metode pengabdian yang dilakukan yaitu ceramah dan dialog. Berdasarkan hasil pretest dan posttest serta menunjukkan bahwa terdapat peningkatan pengetahuan dan motivasi dari peserta, yang terdiri dari tokoh masyarakat, kepala dusun, dan pemerintah desa, untuk mengelola ekosistem mangrove dengan prinsip-prinsip yang berkelanjutan seperti penerapan ekowisata, diversifikasi produk perikanan, dan penyediaan jasa transportasi perahu.
\end{abstract}

Kata kunci - Mangrove, SDGs, Desa Sanjai.

\begin{abstract}
The existence of coastal ecosystems, such as mangroves, if managed properly can provide benefits to the community, especially the surrounding community. However, there is no education related to the use of the mangrove ecosystem so that sometimes people do not really care and tend to carry out extractive activities that can damage the function of the mangrove ecosystem. Sanjai Village is one of the villages located on the coast of Sinjai Regency and has a mangrove ecosystem that has not been managed properly. Based on these problems, this service program aims to improve community knowledge and skills related to the use of mangrove ecosystems through an integrated concept with the principle of Sustainable Development Goals which is a national program. The service method used is lecture and dialogue. Based on the results of the pretest and posttest and shows that there is an increase in the knowledge and motivation of participants, consisting of community leaders, hamlet heads, and village governments, to manage mangrove ecosystems with sustainable principles such as the application of ecotourism, diversification of fishery products, and the provision of services. boat transportation for fishing activities.
\end{abstract}

Keyword-Mangrove, SDGs, Sanjai village.

\section{PENDAHULUAN}

Desa Sanjai terletak di Kecamatan Sinjai Timur Kabupaten Sinjai. Desa Sanjai pada bagian timur berbatasan dengan Teluk Bone sehingga termasuk desa pesisir. Total luas Desa Sanjai yaitu $820,00 \mathrm{Ha}$ dimana pemanfaatan untuk kegiatan persawahan seluas $340,45 \mathrm{Ha}$, 
perkebunan 256,00 $\mathrm{Ha}$, tanah hutan $10,00 \mathrm{Ha}$, fasilitas umum 74,55 Ha, dan tanah kering 139,00 Ha. Secara demografi, penduduk di lokasi pengabdian sebanyak 3.548 jiwa dimana 1.789 diantaranya laki-laki dan 1759 perempuan.

Latar belakang pendidikan penduduk Desa Sanjai didominasi oleh tamatan SD/sederajat $(45,3 \%)$ sedangkan penduduk yang tamat SMA dan melanjutkan perguruan tinggi kurang $7 \%$ dari total penduduk. Kondisi tersebut menyebabkan kurangnya akses informasi masyarakat terhadap inovasi-inovasi yang dihasilkan oleh perguruan tinggi.

Sebagian penduduk di Desa Sanjai berprofesi sebagai nelayan (9\%). Penduduk berprofesi nelayan bermukim di Dusun Takkalala, Dusun Dumme, dan Dusun JahungJahung. Dua dusun lainnya yaitu, Dusun KahuKahu dan Dusun Bisokeng mayoritas penduduknya berprofesi sebagai petani atau pekebun.

Desa Sanjai juga kaya akan kearifan lokal yang dapat menjadi daya tarik wisata. Kearifan lokal tersebut termuat pada adanya ritual Marimpa Salo yang berarti menghalau sungai dimana masyarakat akan bergotong royong turun ke sungai untuk menggiring ikan menggunakan jala dari bagian tengah sungai menuju muara dan ketika tiba di muara maka ikan yang telah digiring tersebut akan ditangkap (Kurnia \& Mustari, 2015).

Ritual yang rutin dilakukan oleh masyarakat di Desa Sanjai tersebut menunjukkan profil masyarakat yang memiliki keterikatan dengan ekosistem pesisir. Ekosistem pesisir yang terjaga dengan baik akan menjadi tempat bagi berbagai jenis ikan untuk memijah sehingga akan tersedia ikan dalam jumlah yang banyak. Namun pengetahuan akan hal tersebut masih terbatas di masyarakat Desa Sanjai sehingga seringkali masyarakat melakukan penebangan bakau pada ekosistem mangrove ataupun melakukan pembukaan lahan tanpa mempertimbangkan keberlanjutan lingkungan.

Upaya untuk menjaga pemanfaatan ekosistem dengan konsep keberlanjutan selaras dengan konsep Sustainable Development Goals (SDGs). Konsep tersebut merupakan suatu kesepakatan global untuk menyusun agenda terkait pembangunan yang berkelanjutan.

Untuk mempercepat capaian terkait agenda SDGs maka pemerintah, melalui Kementerian Desa Pembangunan Daerah Tertinggal dan Transmigrasi, mengeluarkan Peraturan Menteri nomor 13 tahun 2021 yang mewajibkan pemerintah desa agar mengalokasikan dana untuk pemutakhiran data SDGs. Hal tersebut membantu pemerintah pusat untuk meningkatkan pemahaman masyarakat desa terkait konsep SDGs.

SDGs terdiri atas 17 agenda global yang perlu mendapat perhatian masyarakat. Dari 17 agenda tersebut, terdapat setidaknya 3 (tiga) agenda yang berkaitan dengan ekosistem pesisir yaitu agenda 13 (perubahan iklim), agenda 14 (kehidupan bawah air), dan agenda 15 (kehidupan di atas tanah). Keberadaan ekosistem mangrove di Desa Sanjai memungkinkan masyarakat untuk berpartisipasi pada ketiga agenda tersebut mengingat fungsi ekosistem mangrove sebagai penyerap karbon, penahan sedimen dari hulu sungai, dan tempat memijah serta mencari makan berbagai jenis biota.

Desa Sanjai terletak di pesisir dengan panjang pantai $\pm 4 \mathrm{~km}$. Pemanfaatan ekosistem mangrove sejatinya telah dilakukan oleh masyarakat di sekitar lokasi mangrove dengan mengadakan sarana prasarana wisata pantai seperti gazebo dan jalur tracking pada kawasan mangrove. Kawasan tersebut kemudian dikenal dengan Pantai Hubat (Hutan Bakau Takkalala). Akan tetapi pemanfaatan dengan model tersebut tidak relevan terhadap paradigma new tourism dimana wisatawan yang berkunjung juga diberi edukasi dan aktivitas di kawasan tersebut tidak hanya berorientasi pada aktivitas wisata namun juga upaya konservasi (Umam, Sudiyarto, \& Sri, 2015). Paradigma new tourism relevan dengan konsep ekowisata yang pada prinsipnya memberikan wisatawan pengalaman berkunjung ke area alami yang didalamnya terdapat kegiatan konservasi lingkungan dalam rangka meningkatkan kesejahteraan penduduk setempat.

Pemanfaatan ekosistem mangrove dengan prinsip ekowisata sejalan dengan upaya untuk merealisasikan agenda SDGs. Bahkan dengan adanya ekowisata yang dapat meningkatkan perekonomian masyarakat maka pemanfaatan ekosistem mangrove juga berkontribusi terhadap penyelesaiaan agenda 1 yaitu kemiskinan yang selama ini identik dengan masyarakat pesisir. 


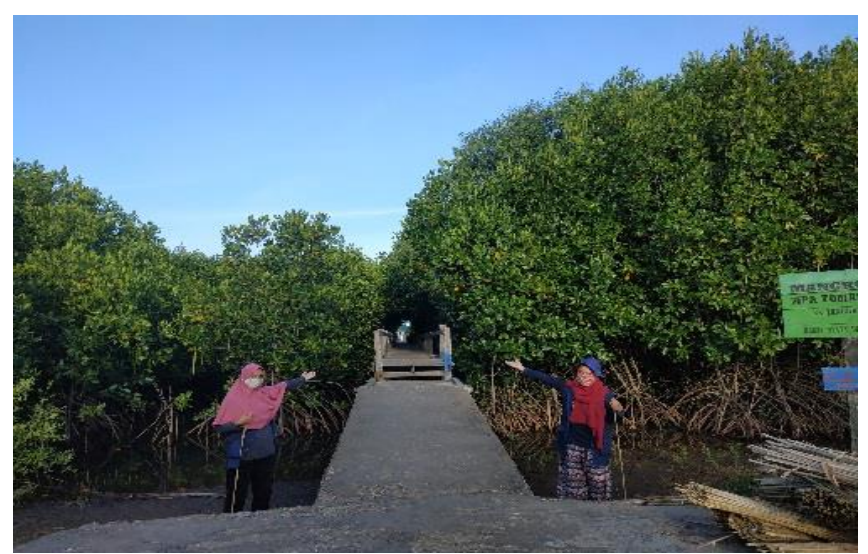

Gambar 1. Ekosistem mangrove di Desa Sanjai

Penelitian (Mukhlisi, 2017) mengungkap potensi jasa lingkungan hutan mangrove yang belum banyak dimanfaatkan untuk dapat dikembangkan dengan konsep ekowisata. (Umam, Sudiyarto, \& Sri, 2015) pada penelitiannya menyimpulkan bahwa strategi yang sesuai untuk pengembangan suatu kawasan ekowisata yaitu melalui strategi agresif dengan menggunakan kekuatan yang dimiliki menghadapi tantangan serta mengatasi kelemahan. Kekuatan utama dari upaya pengembangan kawasan ekowisata yaitu adanya pengetahuan dan komitmen dari masyarakat sekitar lokasi ekowisata untuk menjaga kelestarian lingkungan dan melakukan upayaupaya konservasi (Adriman, Fauzi, El Fajri, Purwanto, \& Prianto, 2020).

Berdasarkan observasi yang telah dilakukan terkait pengelolaan ekosistem mangrove di Desa Sanjai maka ditemui beberapa masalah sebagai berikut :

a. Kurangnya pengetahuan masyarakat terkait pengembangan wisata hutan mangrove

b. Komitmen masyarakat terhadap pengembangan wisata hutang mangrove masing sangat minim sebab dinilai tidak memberi manfaat ekonomis

c. Pihak pemerintah pada berbagai tingkatan (desa, kecamatan, kabupaten) belum terlibat secara aktif dalam pengembangan wisata hutan mangrove

Mengacu pada permasalahan yang telah dikemukakan maka program pengabdian ini memiliki urgensi untuk dilaksanakan dengan memberi penyuluhan kepada stakeholder di Desa Sanjai terkait peluang pemanfaatan ekosistem mangrove dengan mengacu pada konsep berkelanjutan sesuai prinsip SDGs.

\section{METODE PENELITIAN}

Pemilihan metode pengabdian mengacu pada permasalahan dan tujuan yang telah ditetapkan. Metode pengabdian masyarakat yang diimplementasikan yaitu sebagai berikut :

1. Pelaksanaan pre-test dan post-test

Untuk mengukur pengetahuan masyarakat sebelum dan setelah pelaksanaan pengabdian maka dilakukan tes pendahuluan dan tes setelah penyajian materi. Pelaksanaan tes dilakukan dengan memberi pertanyaan yang sama pada tahap pre-test dan post-test agar dapat menilai ada/tidak peningkatan pengetahuan dari peserta. Waktu yang digunakan untuk melaksanakan pre-test dan post-test yaitu masing-masing 15 menit.

2. Pemaparan materi

Materi pada kegiatan pengabdian ini terbagi atas 2 (dua) yaitu materi 1 terkait jasa lingkungan ekosistem mangrove dan SDGs serta materi 2 best practice pengelolaan sumber daya berbasis ekowisata. Pemaparan materi dilakukan dengan metode ceramah selama masing-masing 45 menit. Pada materi 1 dipaparkan mengenai fungsi ekosistem mangrove, peran ekosistem mangrove, urgensi menjaga kelestarian ekosistem mangrove, serta model-model pemanfaatan ekosistem mangrove. Pada materi 2 dipaparkan mengenai praktek pemanfaatan sumber daya alam berbasis ekowisata yang telah dilakukan di berbagai daerah khususnya terkait ekosistem mangrove

3. Sesi diskusi

Untuk penguatan komitmen masyarakat terkait pemanfaatan ekosistem mangrove maka perlu dilakukan brainstorming agar pemateri memperoleh feedback dari masyarakat berdasarkan pengalamannya mengamati dan memanfaatkan ekosistem mangrove di Desa Sanjai. Sesi diskusi akan dibagi dua berdasarkan materi dimana pada alokasi waktu pada setiap sesi diskusi yaitu $30-60$ menit.

Sasaran peserta kegiatan pengabdian ini yaitu aparat pemerintah Desa Sanjai, kepala dusun, ketua RT/RW, kelompok pemuda, dan mahasiswa ITBM Balik Diwa yang sedang berproses melakukan kegiatan Kuliah Kerja Nyata (KKN). Pelaksanaan kegiatan pengabdian dilakukan secara sistematis yaitu melalui tahapan berikut ini :

1. Observasi

Pengamatan terhadap kondisi mangrove di Desa Sanjai dan pola pemanfaatan yang telah dilakukan 
2. Penentuan peserta

Melakukan identifikasi sasaran peserta kegiatan pengabdian dan menentukan jumlah peserta yang ditargetkan hadir

3. Penetapan jadwal kegiatan

Penyesuaian jadwal kegiatan dengan pemerintah desa agar pelaksanaan kegiatan pengabdian dapat dihadiri oleh peserta yang telah diundang

4. Pengadaan sarana prasarana kegiatan

Kegiatan dilaksanakan di aula Desa Sanjai dimana telah tersedia meja, kursi, LCD, dan papan tulis untuk menunjang penyelenggaraan kegiatan pengabdian serta perlengkapan pendukung penerapan protokol kesehatan seperti masker bagi peserta dan hand-sanitizer.

5. Pelaksanaan kegiatan

Kegiatan dilaksanakan sesuai jadwal kegiatan yang telah disepakati sebelumnya antara pihak ITBM Balik Diwa dan pemerintah Desa Sanjai

\section{HASIL DAN PEMBAHASAN}

Kegiatan penyuluhan terkait pemanfaatan ekosistem mangrove diadakan pada November 2021. Pelaksanaan kegiatan bertempat di aula Desa Sanjai yang berdampingan dengan Kantor Desa Sanjai. Pelaksanaan kegiatan mematuhi protokol kesehatan dengan menjaga jarak dan memakai masker. Aula tempat pelaksanaan kegiatan memungkinkan untuk diisi oleh 50 orang dengan menerapkan protokol kesehatan.

Hadir sebagai narasumber yaitu Rahmat Januar Noor,S.Si.,M.Si menyajikan materi tentang Model Pemanfaatan Ekosistem Mangrove sekaligus sebagai penulis. Pemateri kedua yaitu Muhammad Imran Lapong, S.Kel.,M.Si membawakan materi tentang Best Practice Ekowisata. Pemateri ketiga yaitu Arnold Kabangnga,S.Pi.,M.Si membawakan materi tentang Prinsip-Prinsip SDGs.

Kegiatan pengabdian diawali dengan sambutan dari Kepala Desa Sanjai, bapak A. Muhammad Arsal, S.Ip. Pada sambuatannya telah diuraikan terkait kebijakan desa dalam memanfaatkan ekosistem mangrove. Setelah penyampaian sambutan maka dilanjutkan dengan pemaparan materi dari tim pengabdi.

Hasil dari pelaksanaan kegiatan pengabdian diuraikan sebagai berikut.

1. Kehadiran masyarakat

Adapun deskripsi peserta kegiatan berdasarkan asal instansi atau unit kerja dapat diperhatikan pada tabel berikut.

Tabel 1. Deskripsi peserta

\begin{tabular}{|l|c|c|}
\hline \multicolumn{1}{|c|}{ Instansi Asal } & Frekuensi & Persen \\
\hline Kantor Desa Sanjai & 6 & $17,14 \%$ \\
\hline Kepala Dusun & 5 & $14,29 \%$ \\
\hline $\begin{array}{l}\text { Tokoh Masyarakat/Adat/ } \\
\text { Agama }\end{array}$ & 3 & $8,57 \%$ \\
\hline Karang Taruna & 5 & $14,29 \%$ \\
\hline Kelompok Nelayan & 5 & $14,29 \%$ \\
\hline BUMDes & 2 & $5,71 \%$ \\
\hline Masyarakat & 9 & $25,71 \%$ \\
\hline \multicolumn{1}{|c|}{ Jumlah } & 35 & $100,00 \%$ \\
\hline \multicolumn{2}{|c|}{}
\end{tabular}

Peserta kegiatan penyuluhan sesuai dengan target pelaksanaan yaitu stakeholders di Desa Sanjai. Kehadiran berbagai elemen masyarakat mulai dari pemerintah, tokoh masyarakat, pemuda, serta masyarakat baik kelompok maupun individu pada kegiatan pengabdian bertema ekosistem mangrove yang dilakukan menunjukkan antusiasme masyarakat terkait pemanfaatan ekosistem mangrove.

Antusias masyarakat mengikuti kegiatan mengindikasikan bahwa masyarakat memiliki pengetahuan terkait keberadaan ekosistem mangrove. Melalui adanya kegiatan pengabdian maka diharapkan pengetahuan masyarakat terkait ekosistem mangrove akan meningkat.

\section{Peningkatan pengetahuan}

Untuk mengetahui peningkatan pengetahuan masyarakat terkait ekosistem mangrove maka dilakukan pre-test dan post-test yang telah dirancang oleh tim pengabdian. Hasil pre-test dan post-test dapat diperhatikan pada grafik berikut.

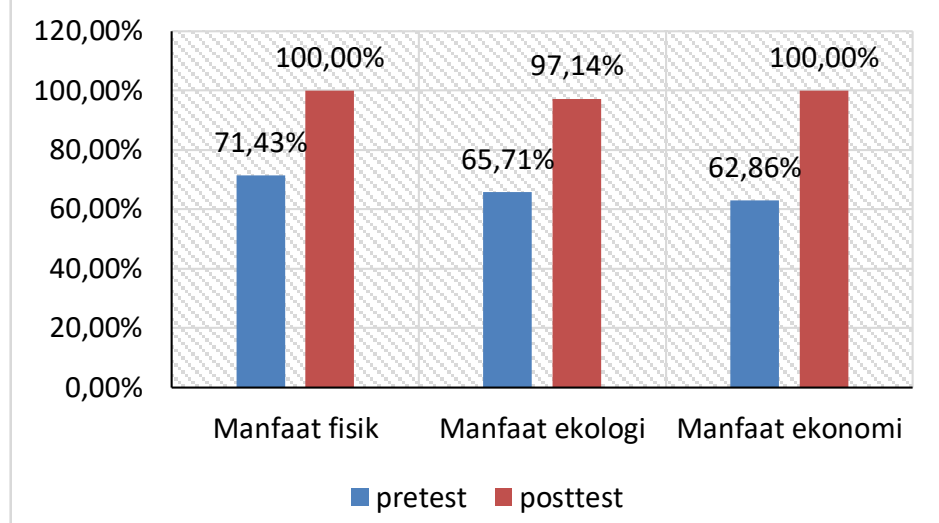

Gambar 2. Grafik hasil pre-test dan post-test

Hasil pre-test menunjukkan bahwa masyarakat memiliki pemahaman yang cukup baik terkait manfaat ekosistem mangrove secara 
fisik, ekologi, dan ekonomi. Pada sesi pre-test terlihat bahwa masyarakat paling memahami terkait manfaat fisik dari ekosistem mangrove. Masyarakat Desa Sanjai sebagian besar bermukim di pesisir yang memiliki struktur vegetasi didominasi oleh mangrove sehingga masyarakat telah memperoleh manfaat dari keberadaan mangrove secara langsung maupun tidak langsung utamanya manfaat fisik. Manfaat fisik dari ekosistem mangrove yaitu sebagai pelindung garis pantai dari abrasi, penahan sedimen, dan mereduksi kecepatan arus serta gelombang (Mayasari, Pribadi, \& Soenardjo, 2021).

Pada hasil post-test dapat diperhatikan bahwa terdapat peningkatan pengetahuan peserta terkait pemanfaatan ekosistem mangrove. Pada pengetahuan terkait manfaat fisik dan manfaat ekonomi terjadi peningkatan pengetahuan pada seluruh peserta kegiatan pengabdian sedangkan pada manfaat ekologi terjadi peningkatan menghampiri $100 \%$. Peningkatan tersebut menunjukkan ketercapaian materi yang diberikan oleh narasumber dari tim pelaksana pengabdian terkait pemanfaatan mangrove.

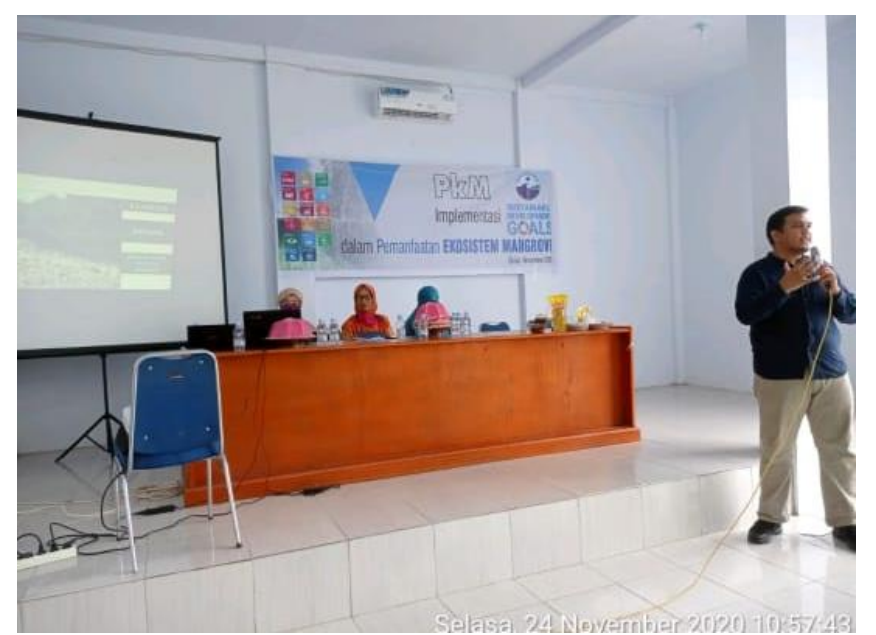

Gambar 3. Pemaparan materi oleh salah satu narasumber

Berdasarkan hasil brainstorming pada sesi diskusi dengan peserta maka diketahui bahwa pantai di pesisir Dusun Takkalala, Desa Sanjai telah dimanfaatkan sebagai lokasi wisata yang diintegrasikan dengan keberadaan ekosistem mangrove. Selain itu, masih terdapat masyarakat yang melakukan penebangan terhadap mangrove dengan tujuan dijadikan kayu bakar ataupun pembukaan lahan untuk dialihfungsikan. Mengacu pada hasil diskusi tersebut maka dapat disimpulkan sementara bahwa pemanfaatan ekosistem mangrove di Desa Sanjai belum dilakukan secara berkelanjutan.
3. Perubahan perilaku masyarakat

Untuk memberi pemahaman kepada peserta maka narasumber kedua memberikan gambaran terkait pemanfaatan ekosistem mangrove yang sesuai prinsip-prinsip konservasi. Lokasi yang dijadikan contoh yaitu pemanfaatan ekosistem mangrove di Kelurahan Tekolabbua, Kota Makassar dan Desa Tongke-Tongke, Kabupaten Sinjai. Adanya contoh lokasi pemanfaatan ekosistem mangrove yang berkelanjutan dapat memberi gambaran nyata kepada masyarakat terkait teknis pemanfaatan ekosistem mangrove.

Selain teknis pemanfaatannya, peserta juga diperlihatkan adanya peningkatan manfaat ekonomi yang diterima dengan adanya pemanfaatan ekosistem mangrove yang tidak ekstraktif. Beberapa kegiatan yang dapat memberi manfaat ekonomi bagi masyarakat yaitu pembibitan mangrove, penyediaan makanminum, jasa sewa perahu, dan jasa penginapan. Selain bagi masyarakat, pemerintah Desa Sanjai juga dapat memperoleh manfaat dengan bekerjasama dengan instansi terkait untuk meningkatkan pendapatan asli desa melalui pengelolaan pemanfaatan ekosistem mangrove secara terorganisir (Agungguratno \& Darwanto, 2016). Pihak pemerintah Desa Sanjai memberi tanggapan positif terkait hal tersebut dan berkomitmen untuk menyelenggarakan pengelolaan ekosistem mangrove berbasis konservasi.

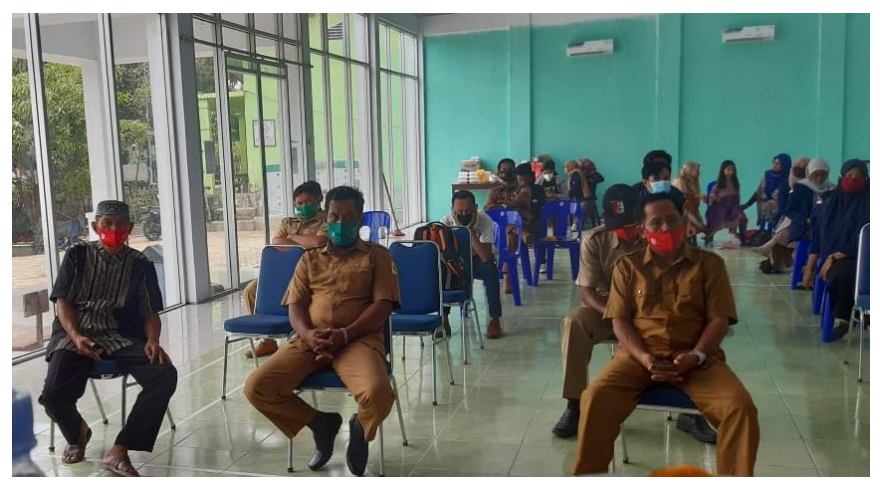

Gambar 4. Suasana peserta kegiatan pengabdian

Pengelolaan ekosistem mangrove berbasis konservasi merupakan bagian dari agenda SDGs sebagaimana diuraikan oleh narasumber ketiga. Adanya agenda SDGs yang terintegrasi dengan upaya pemerintah desa dalam mengelola ekosistem mangrove akan menjadi kelebihan tersendiri bagi pemerintah Desa Sanjai sebagai kontribusi dalam pencapaian target SDGs pemerintah pusat. 


\section{Keberlanjutan program}

Program pengabdian yang telah dilakukan kemudian menjadi acuan bagi mahasiswa untuk melaksanakan kegiatan Kuliah Kerja Nyata (KKN) di Desa Sanjai. Beberapa program terkait pemanfaatan ekosistem mangrove yang telah dilakukan yaitu pengadaan fasilitas penanda lokasi ekowisata mangrove berupa gerbang dan papan informasi, papan penunjuk fasilitas (kamar mandi, parkiran), pengadaan tempat sampah, pengadaan spot foto, dan penanaman mangrove.

\section{KESIMPULAN DAN SARAN}

Pelaksanaan kegiatan pengabdian oleh tim pengabdi ITBM Balik Diwa memperoleh respon positif dari pemerintah dan masyarakat. Melalui kegiatan pengabdian yang telah dilakukan maka diketahui telah terjadi peningkatan pengetahuan masyarakat terkait pemanfaatan ekosistem mangrove. Pemerintah Desa Sanjai juga telah menunjukkan komitmen untuk mengembangkan kawasan wisata Pantai Hutan Bakau Takkalala dengan menerapkan prinsip-prinsip konservasi agar meningkatkan kesejahteraan masyarakat pesisir dan pendapatan asli desa. Pemerintah desa juga memberi respon positif dengan mendukung pelaksanaan kegiatan Kuliah Kerja Nyata (KKN) ITBM Balik Diwa Makassar di Desa Sanjai.

Berdasarkan uraian hasil kegiatan dan kesimpulan maka beberapa saran yang dapat diberikan antara lain :

1. Durasi pelaksanaan kegiatan pengabdian diperpanjang dan dilakukan secara berkala untuk mengetahui ketercapaian materi yang telah diabdikan kepada masyarakat

2. Program pengabdian terintegrasi dengan pelaksanaan Kuliah Kerja Nyata (KKN) merupakan model ideal untuk memudahkan diseminasi pengetahuan dan teknologi dari perguruan tinggi ke pemerintah desa dan masyarakat

3. Potensi desa perlu dianalisis lebih mendalam untuk menyusun program pengabdian yang lebih komprehensif dimana hal tersebut dapat dilakukan melalui penyusunan dan penandatanganan nota kesepahaman antara perguruan tinggi dan pemerintah desa

\section{DAFTAR PUSTAKA}

Adriman, Fauzi, M., El Fajri, N., Purwanto, E., \&
Volume 1 Namar 1 Tahun 2021

Prianto, E. (2020, Desember 1). PENYULUHAN KONSERVASI HUTAN MANGROVE DI DESA MENGKAPAN KECAMATAN SUNGAI APIT KABUPATEN SIAK. Journal of Rural and Urban Community Empowerment, 2(1), 42-49.

Agungguratno, E. Y., \& Darwanto. (2016). Penguatan Ekosistem Mangrove untuk Pemberdayaan Ekonomi Masyarakat Pesisir. EKO-REGIONAL, 11(1), 1-9.

Kurnia, A., \& Mustari. (2015, September). Pelaksanaan Tradisi Marimpa Salo pada Masyarakat Desa Sanjai Kecamatan Sinjai Timur Kabupaten Sinjai. Tomalebbi, 2(2), 19-23. Retrieved from https://ojs.unm.ac.id/index.php/tomalebbi/ article/view/1710

Mayasari, V. F., Pribadi, R., \& Soenardjo, N. (2021, Februari). Valuasi Ekonomi Ekosistem Mangrove di Desa Timbulsloko Kecamatan Sayung Kabupaten Demak. Buletin Oseanografi Marina, 10(1), 42-50.

Mukhlisi. (2017, Januari). Potensi Pengembangan Ekowisata Mangrove di Kampung Tanjung Batu, Kecamatan Pulau Derawan, Kabupaten Berau. J. Manusia \& Lingkungan, 24(1), 23-30. doi:http://dx.doi.org/10.22146/jml.18811

Umam, K., Sudiyarto, \& Sri, T. W. (2015). Strategi Pengembangan Ekowisata Mangrove Wonorejo Surabaya. Jurnal AGRARIS, $\quad 1(1), \quad 38-42$. doi:10.18196/agr.116 